7 Logan WPD, Cushion AA. General Register Office Studies on Medical and Population Subjects: Report No 14: Morbidity Statistics from General Practice. London: HMSO, 1958.

8 Kraepelien S. The frequency of bronchial asthma in Swedish school children. Acta Paediatr 1954;43(Suppl 100): 149-53.

9 Eilertsen E. Astmahyppighet et skolebarnsmateriale fra Bergen. Tiedsskr Norske Laegefor 1954:73:322-8.

10 Peltonen M-L, Kasanen A, Peltonen TE. Occurrence of allergic conditions in schoolchildren. Ann Pediatr Fenn 1955;1:119-29.

11 Erikssohn-Lihr Z. Special features of allergy in children. Acta Allergol 1955;8:289-313.

12 Graham PJ, Rutter ML, Yule W, et al. Childhood asthma: a psychosomatic disorder? Some epidemiological considerations. Br J Prev Soc Med 1967;21:78-85.

13 Dawson B, Illsley R, Horobin G, et al. A survey of childhood asthma in Aberdeen. Lancet 1969;1:827-30.

14 Hartley D, Jack D, Lunts LHC, et al. New class of selective stimulators of $\beta$-adrenergic receptor. Nature 1968:219:861-2.

15 Gregg I. Disodium cromoglycate in bronchial asthma. Lancet 1968;2:350-1.
16 Brown HM, Storey G, George WH. Beclomethasone dipropionate: a new steroid aerosol for the treatment of allergic asthma. BMJ 1972;1:585-90

17 Lee DA, Winslow NR, Speight AN, et al. Prevalence and spectrum of asthma in childhood. BMJ (Clin Res Ed) 1983;286:1256-8.

18 Speight AN, Lee DA, Hey EN. Underdiagnosis and undertreatment of asthma in childhood. BMJ (Clin Res Ed) 1983;286:1253-6.

19 Anderson HR. Increase in hospitalisation for childhood asthma. Arch Dis Child 1978:53:295-300.

20 Mitchell EA. International trends in hospital admission rates for asthma. Arch Dis Child 1985:60:376-8

21 Smith JM. The prevalence of asthma and wheezing in children. $\mathrm{Br} J$ Dis Chest 1976;70:73-7.

22 Magnus $\mathbf{P}$, Jaakkola JJ. Secular trend in the occurrence of asthma among children and young adults: critical appraisal of repeated cross sectional surveys. BMJ 1997:314:1795-9.

23 Burr ML, Butland BK, King S, et al. Changes in asthma prevalence: two surveys 15 years apart. Arch Dis Child 1989;64:1452-6.
24 Strachan DP. Hay fever, hygiene, and household size. BMJ 1989:299:1259-60.

25 Van Niekerk CH, Weinberg EG, Shore SC, et al. Prevalence of asthma: a comparative study of urban and rural Xhosa children. Clin Allergy 1979:9:319-4.

26 Strachan DP. Family size, infection and atopy: the first decade of the "hygiene hypothesis". Thorax 2000;55(Suppl 1):S2-10.

27 Omran M, Russell G. Continuing increase in respiratory symptoms and atopy in Aberdeen schoolchildren. BMJ 1996;312:34.

28 Devenny AM, Wassall HJ, Ninan TK, et al. Respiratory symptoms and atopy in children in Aberdeen: questionnaire studies of a defined school population repeated over 35 years. BMJ 2004;329:489-90.

29 Toelle BG, Marks GB. The ebb and flow of asthma. Thorax 2005;60:87-8.

30 Burr ML, Wat D, Evans C, et al. Asthma prevalence in 1973, 1988 and 2003. Thorax 2006;61:296-9

31 Hill R, Williams $J$, Tattersfield $A$, et al. Change in use of asthma as a diagnostic label for wheezing illness in schoolchildren. BMJ 1989;299:898.

32 Lenney $\mathrm{W}$. The burden of pediatric asthma. Pediatr Pulmonol (Suppl) 1997;15:13-6.

\title{
Training in the operating theatre: is it safe?
}

\section{R Aggarwal, A Darzi}

\section{The importance of a systems approach to surgical training}

$\mathrm{R}$ cent years have witnessed a number of drivers for change in the delivery of health care. ${ }^{1}$ Working time restrictions, quality assurance targets, the introduction of new technologies and star ratings for hospitals have served to create antagonism between service and training priorities. The provision of a high quality service necessitates the employment of proficient practitioners, using tools to the highest of their abilities. This is in discord with the apprenticeship model of training whereby trainees undergo graded practice on patients, leading to the development of proficiency. ${ }^{2}$ Furthermore, a number of high profile cases have highlighted the need for regular audit of outcomes to ensure patient care is not compromised. ${ }^{3}$

It is well known that achievement of proficiency to perform a procedure entails a learning curve during which morbidity and mortality gradually decline. ${ }^{45}$ However, some of the complications which occur during the learning curve are avoidable through appropriate case selection and adequate supervision during the procedure. In the example offered by Chaudhuri et $a l^{6}$ in this issue of Thorax, trainee thoracic surgeons led over one third of the cases of lung resection. A comparison of outcomes revealed similar rates of complications and survival at 1 year. In terms of case selection, consultants operated on greater numbers of stage III tumours and trainees on a greater number of stage I tumours.

This study echoes the main features of the apprenticeship model which has been a cornerstone of skills acquisition in surgical disciplines. The key principle is to ensure patient safety whilst enabling the trainee surgeon to acquire and hone skills to perform the procedure. The notion of a graded approach allows trainees to acquire skills in a stepwise manner, through close supervision by a senior surgeon. It is the responsibility of the senior surgeon to ensure the patient does not come to any undue harm. Upon achievement of proficiency, the trainee can proceed onto performing more complex cases, eventually gaining the ability to operate independently.

Although the apprenticeship model has stood the test of time, the incorporation of new technologies for technical skills training outside the operating room can further improve patient safety. ${ }^{7}$ In analogy with the airline industry, it is now possible for trainees to acquire basic skills which transfer to improved performance in the operating suite. ${ }^{8-11}$ It is no longer appropriate (nor acceptable) to have a surgeon dithering in theatre. The trainee must know the basic skills and be able to undertake complex manoeuvres by the time he comes to the operating theatre. With the incorporation of simulation based training earlier in the curriculum, it may also be possible to reduce the length of the learning curve for the achievement of proficiency on real cases.

Upon achievement of proficiency in the skills laboratory, training must continue in a structured manner in the operating room. Graded exposure along with appropriate support when necessary is most effective in transferring skills from tutor to student. This should also not be limited to the operating theatre, but augmented by discussions and feedback before and after each case. In addition, the postoperative dialogue of each procedure can be supported by video footage of the operation. Thus, the model is still recognisable as graded exposure in the operating suite, but amplified by a number of other factors.

For each interventional speciality, outcomes from a key procedure are traditionally used as markers of an individual surgeon's technical performance. However, this approach is too simplistic and fails to take account of the numerous factors which can affect patient outcomes. $^{12}$ Patient characteristics can decrease or increase the risk of complications, especially during major surgical procedures. This can be accounted for through appropriate case selection, ensuring that the sickest or most complex patients are operated upon by the most experienced surgeons. However, it 
is not only the surgeon who needs to be experienced to ensure an optimal outcome-the rest of the operating team can also have a significant impact on the outcome of the procedure. This is none more so than for minimally invasive procedures whereby the surgeon must rely upon the camera positioning skills of another individual. For cardiothoracic surgery, an experienced anaesthetist is crucial for those cases where the patient has minimal physiological reserves. Recent work has also shown that postoperative and ward care has a considerable impact on patient outcomes. ${ }^{13}$

In the study of outcomes following lobectomy by Chaudhuri et al, ${ }^{6}$ surgical skill has been assessed indirectly by way of complications and mortality at 1 year. Although extensively used as a marker of technical expertise, this strategy lacks objectivity. Our department has pioneered the use of motion tracking and video based assessment of technical skills in surgical disciplines. ${ }^{14}$ With this approach it is possible to tease out individual factors which contribute to eventual patient outcome. A review of the interactions between the individuals in the operating suite and a closed circuit camera system can serve to elucidate other factors such as communication and team dynamics. ${ }^{15}$ The delivery of ward care can also be assessed through review of medical notes immediately after discharge of the patient. It is then possible not only to determine the skills of the surgeon, but also to identify any other deficiencies which may have led to sub-standard outcomes. The primary aim of a systems approach to surgical safety is to identify and reduce errors which could lead to poor outcomes.

The study by Chaudhuri et al concentrated specifically on a comparison between cases led by trainees or consultants. ${ }^{6}$ Its aim was to investigate whether it was appropriate, in terms of patient outcomes, to allow trainees to be the primary operator for complex thoracic procedures. A further focus of an outcomes database would be to analyse data for individual surgeons, ensuring high quality care across the board. This would be in synchrony with assessment of the other factors mentioned previously which also contribute to patient outcomes. Furthermore, the impact of specialist versus generalist surgeons, modifications to surgical technique, and new technologies could be accurately assessed, providing information not only to the surgeon but also to patients regarding their mode of treatment.

In summary, training in the operating theatre is a critical part of developing skills toward independent practice. The apprenticeship model of training through graded exposure can be safe, but should be augmented with simulation based practice, adequate supervision, and constructive feedback following each case. Analysis of outcomes data can ensure patient safety is not compromised, but should be placed within the wider multifactorial context of patients. It is only with this approach that we can provide the utmost level of care and continue to produce competent practitioners of the future.

Thorax 2006;61:278-279

doi: 10.1136/thx.2005.051789

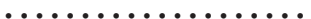

Authors' affiliations

R Aggarwal, A Darzi, Department of Biosurgery and Surgical Technology, Imperial College London, St Mary's Hospital, London, UK

Correspondence to: Mr R Aggarwal, Department of Biosurgery and Surgical Technology, Imperial College London, St Mary's Hospital, London W2 INY, UK: rajesh.aggarwal@imperial.ac.uk

Funding: none.

Competing interests: none declared.

\section{REFERENCES}

1 Aggarwal R, Hance J, Darzi A. Surgical education and training in the new millennium. Surg Endosc 2004: 18: 1409-10.

2 Halsted WS. The training of the surgeon Bull Johns Hopkins Hosp 1904; 15:267-75.

3 Smith R. All changed, changed utterly. British medicine will be transformed by the Bristol case. BMJ 1998;316:1917-8.

4 A prospective analysis of 1518 laparoscopic cholecystectomies. The Southern Surgeons Club. N Engl J Med 1991;324:1073-8.

5 Tekkis PP, Senagore AJ, Delaney CP, et al. Evaluation of the learning curve in laparoscopic colorectal surgery: comparison of right-sided and left-sided resections. Ann Surg 2005;242:83-91.

6 Chaudhuri N, Grayson AD, Grainger R, et al. Effect of training on patient outcomes following lobectomy. Thorax 2006:61:327-30.

7 Satava RM. Surgical education and surgical simulation. World J Surg 2001;25:1484-9.

8 Blum MG, Powers TW, Sundaresan S. Bronchoscopy simulator effectively prepares junior residents to competently perform basic clinical bronchoscopy. Ann Thorac Surg 2004:78:287-91.

9 Grantcharov TP, Kristiansen VB, Bendix J, et al. Randomized clinical trial of virtual reality simulation for laparoscopic skills training. Br J Surg 2004:91:146-50.

10 Sedlack RE, Kolars JC. Computer simulator training enhances the competency of gastroenterology fellows at colonoscopy: results of a pilot study. Am J Gastroenterol 2004;99:33-7.

11 Seymour NE, Gallagher AG, Roman SA, et al Virtual reality training improves operating room performance: results of a randomized, double-blinded study. Ann Surg 2002;236:458-63.

12 Vincent C, Moorthy K, Sarker SK, et al. Systems approaches to surgical quality and safety: from concept to measurement. Ann Surg 2004;239:475-82.

13 Jones HJ, Coggins R, Lafuente J, et al. Value of a surgical high-dependency unit. Br J Surg 1999:86:1578-82.

14 Aggarwal R, Moorthy K, Darzi A. Laparoscopic skills training and assessment. Br J Surg 2004;91:1549-58.

15 Aggarwal R, Undre S, Moorthy K, et al. The simulated operating theatre: comprehensive training for surgical teams. Qual Saf Health Care 2004; 13(Suppl I):i27-32. 